\title{
Predictive Factors for Benign Lesions in Partially or Radically Resected Kidneys in a Single Independent Cancer Center
}

\author{
Norihito Soga Yuji Ogura Norio Hayashi \\ Institution Aichi Cancer Center, Department of Urology, Nagoya, Japan
}

\section{Key Words}

Benign nodule Predictive factor $\cdot$ Renal cancer

\begin{abstract}
Objective: To assess the incidence and predictive factors of benign renal lesions in surgical specimens obtained at our institution. Methods: We carried out a retrospective assessment of 96 renal nodules, diagnosed by dynamic multi-detector row helical computed tomography, and resected by either radical or partial nephrectomy between January 2004 and November 2011. The incidence of benign lesions in 1-cm increments of diameter was determined and the predictive factors for these lesions were then evaluated. Results: Of the 96 nodules, histology confirmed that 13 (13.5\%) were benign. The incidence of benign lesions was $25.0 \%$ for nodules $<1 \mathrm{~cm}, 23.8 \%$ for nodules $1-1.9 \mathrm{~cm}, 11.5 \%$ for nodules $2-2.9$ $\mathrm{cm}, 7.7 \%$ for nodules $3-3.9 \mathrm{~cm}$, and $7.1 \%$ for nodules $\geq 4 \mathrm{~cm}$. Multivariate analysis showed that younger age ( $<60$ years; odds ratio $[O R]=5.23)$, female gender $(O R=4.78)$, and smaller nodule size $(<3 \mathrm{~cm} ; \mathrm{OR}=6.14)$ were significant predictive factors for benign lesions. Conclusions: The incidence of benign lesions in this study ( $13.5 \%$ of total cases) was relatively low compared with recent studies from Western countries that reported an incidence of 15-20\%. Significant predictive factors for benign lesions included younger age, female gender, and smaller tumor size.
\end{abstract}

Copyright $\odot 2013$ S. Karger AG, Basel

\section{KARGER}

Fax +41613061234

E-Mail karger@karger.ch

www.karger.com
(C) 2013 S. Karger AG, Base

$1015-9770 / 13 / 0072-0070 \$ 38.00 / 0$

Accessible online at:

www.karger.com/cur

\section{Introduction}

Reports from Western countries have shown that 15$20 \%$ of small renal nodules are benign [1-3]. In contrast, recent studies on Japanese cases have reported lower incidences of benign tumors in small resected renal masses $[4,5]$.

These results indicate that the prevalence of benign lesions may differ depending on several factors, including ethnic background, the method used for radiological evaluation, and the incidence of specific types of benign tumors, such as oncocytomas or angiomyolipomas.

It is possible that the incidence of benign tumors can be markedly affected by radiological instruments and the diagnostic steps used at each institution. In addition, dynamic imaging using multi-detector row helical computed tomography (CT) is common and indispensable for evaluating renal nodules $[6,7]$. In order to devise management strategies, it is therefore crucial to determine the incidence of benign tumors in suspicious renal masses detected by new standard imaging technology.

The current retrospective study was designed to provide new information on clinical management of suspicious renal nodules, and also to prepare local databases of preoperative factors that predicted the probability of benign lesions.

In this paper, we describe the incidence and predictive factors of benign renal nodular lesions obtained by surgical resection. 
Table 1. Baseline characteristics of the patients in the study

\begin{tabular}{ll}
\hline Patient demography & \\
\hline Number of cases & 96 \\
Number of masses & 96 \\
Age, years (range) & $59.8 \pm 10.5(30-81)$ \\
$<60$ & $52(54.1 \%)$ \\
60 & $44(45.8 \%)$ \\
Gender, $\%$ & \\
Male & $59(61.4 \%)$ \\
Female & $37(38.4 \%)$ \\
Tumor site, \% & \\
Right & $47(49.0 \%)$ \\
Left & $49(51.0 \%)$ \\
Mean maximum diameter, cm (range) & $3.7 \pm 2.7(0.9-20.0)$ \\
Surgical procedure (\%) & \\
Radical nephrectomy & $87(90.6 \%)$ \\
Partial nephrectomy & $9(9.4 \%)$ \\
Benign total (\%) & $13(13.5 \%)$ \\
Oncocytoma & $6(6.2 \%)$ \\
Angiomyolipoma & $5(5.2 \%)$ \\
Solitary fabrous tumor & $1(1.0 \%)$ \\
Schwannoma & $1(1.0 \%)$ \\
Malignancy total (\%) & $83(86.4 \%)$ \\
Clear cell & $75(78.1 \%)$ \\
Papillary & $2(2.1 \%)$ \\
Cystic & $2(2.1 \%)$ \\
Chromophobe & $0(0.0 \%)$ \\
Unclassified & $4(4.2 \%)$ \\
\hline
\end{tabular}

\section{Patients and Method}

Study Design

This retrospective study was undertaken at one independent institution, with informed consent being obtained from each patient. Ninety-six consecutive patients with 96 renal masses were enrolled in the study. The patients underwent either a radical or partial nephrectomy because of preoperative suspicion of renal cell carcinoma (RCC) between January 2004 and November 2011.

The radiographic appearance of the renal mass was initially evaluated by ultrasonography and dynamic multi-detector row helical CT. If a preoperative diagnosis could not be established using this radiological approach, dynamic magnetic resonance imaging (MRI) was carried out to provide further details. Dynamic studies were used to obtain detailed images of the degree of enhancement and wash-out. The scans recorded 3 phases following a bolus infusion of contrast material at a rate of $3 \mathrm{ml} / \mathrm{s}$. For dynamic MRI, the 3 phases were obtained following a bolus infusion of gadolium chelate at a rate of $0.1 \mathrm{mmol} / \mathrm{kg}$. The administration rate was $100 \%$ for cases investigated by ultrasonography and dynamic CT and $49 \%$ for cases investigated by dynamic MRI.

Surgery was performed for preoperative suspicion of RCC based on the following criteria: 1) Solid enhanced masses (increase of 10 Hounsfield units within the renal lesion); 2) Masses without intra-tumor fat in order to exclude angiomyolipomas; 3 )

Incidence and Predictive Factors of Benign Renal Nodules
Table 2. Benign lesions grouped according to size

\begin{tabular}{lcl}
\hline Tumor size, $\mathrm{cm}$ & Total number, $\mathrm{n}$ & Benign, $\mathrm{n}(\%)$ \\
\hline $0.0-0.9$ & 8 & $2(25.0 \%)$ \\
$1.0-1.9$ & 21 & $5(23.8 \%)$ \\
$2.0-2.9$ & 26 & $3(11.5 \%)$ \\
$3.0-3.9$ & 13 & $1(7.7 \%)$ \\
4.0 or greater & 28 & $2(7.1 \%)$ \\
\hline
\end{tabular}

Complicated renal cysts of type III or IV (Bosniak classification [8]) detected by radiological imaging.

Exclusion criteria included a genetic predisposition for von Hippel-Lindau disease or Birt-Hogg-Dube syndrome, a tumor biopsy, primary urothelial cell carcinoma, metastatic tumors, or tuberous sclerosis. Four cases were excluded.

Surgical procedures were not carried out when the tumors were diagnosed preoperatively as benign, based on radiological evaluation. These cases were followed-up under close radiological examination for at least 1 year. Cases without radiological evidence of alterations in size and enhancement were diagnosed as clinically benign. In addition, since all the big tumors $(>4 \mathrm{~cm})$ in this study were suspected to be angiomyolipomas with fat components, estimation of alteration in size and enhancement might be enough to diagnose benign histology in the follow-up protocol.

The specimens resected by partial or radical nephrectomy were assessed using pathological measurements to determine the largest diameter $(\mathrm{cm})$ and the pathological subtype was estimated using the 2004 WHO classification.

Standard staining with Hale's colloidal iron was carried out in order to distinguish between oncocytomas and chromophobe RCCs.

Statistical Analysis

The Chi-square test was used to compare variations in categorical variables. Logistic univariate and multivariate regression models were used to analyze the relationships between the incidence of benign lesions and other factors. A p-value $<0.05$ was considered statistically significant. Statistical analyses were performed using SPSS version 15 (SPSS, Chicago, IL, USA).

\section{Results}

Between January 2004 and November 2011, 96 consecutive patients with 96 suspicious renal masses underwent radical or partial nephrectomy at our institution. The background of the patients and characteristics of the tumors are summarized in table 1 . The mean age of the patient group was 59.8 years (range $30-81$ years), and mean maximum nodule diameter was $3.7 \mathrm{~cm}$ (range $0.9-20.0 \mathrm{~cm}$ ). Open partial nephrectomy was performed in $9(9.4 \%)$ cases and open radical nephrectomy in 87 $(90.6 \%)$ cases. The incidence of benign lesions was $13.5 \%$ in all cases. 
Table 3. Logistic analysis of predicitors for benign renal masses

\begin{tabular}{|c|c|c|c|c|c|c|}
\hline & \multicolumn{3}{|c|}{ Univariate model } & \multicolumn{3}{|c|}{ Multivariate model } \\
\hline & Odds ratio & $95 \% \mathrm{CI}$ & $\mathrm{p}$ & Odds ratio & $95 \% \mathrm{CI}$ & $\mathrm{p}$ \\
\hline Age, years $(<60$ vs. 60$)$ & 3.71 & $1.11-12.47$ & 0.034 & 5.23 & $1.23-21.77$ & 0.023 \\
\hline Gender (female vs. male) & 3.98 & $1.13-14.01$ & 0.032 & 4.78 & $1.12-20.56$ & 0.035 \\
\hline Tumor size,cm (<3.0 vs. 3.0$)$ & 5.89 & $1.50-23.08$ & 0.01 & 6.14 & $1.34-28.15$ & 0.019 \\
\hline Imaging type (CT vs. CT with MRI) & 2.26 & $0.76-9.34$ & 0.13 & 1.54 & $0.39-6.19$ & 0.548 \\
\hline
\end{tabular}

Table 4. Summary of the risk factors for the presence of benign renal lesions

\begin{tabular}{lclcl}
\hline Reports & Tumor, $\mathrm{n}$ & Operation & Benign (\%) & Risk factor \\
\hline Snyder et al. 2006 [1] & 815 & $\mathrm{RN}+\mathrm{PN}$ & $134(16.4 \%)$ & female \\
Jeon et al. 2010 [2] & 376 & $\mathrm{PN}$ & $81(21.5 \%)$ & female, yonger age, time of surgery (before 2006) \\
Akdogan et al. 2012 [3] & 450 & $\mathrm{RN}+\mathrm{PN}$ & $88(19.9 \%)$ & size $(2 \mathrm{~cm})$, female, NSS \\
Soga et al. 2012 [5] & 411 & $\mathrm{RN}+\mathrm{PN}$ & $18(4.4 \%)$ & size $(<2 \mathrm{~cm})$, female \\
Xiong et al. 2010 [12] & 303 & $\mathrm{RN}+\mathrm{PN}$ & $31(10.2 \%)$ & size $(4 \mathrm{~cm})$, female \\
Present study & 96 & $\mathrm{RN}+\mathrm{PN}$ & $13(13.5 \%)$ & size $(<3 \mathrm{~cm})$, female, age $(<60$ years $)$ \\
\hline
\end{tabular}

NSS = Nephron-sparing surgery; RN = radical nephrectomy; $\mathrm{PN}=$ partial nephrectomy.

Histological examination confirmed a total of 13 $(13.5 \%)$ benign lesions, consisting of $6(6.2 \%)$ oncocytomas, $5(5.2 \%)$ angiomyolipomas, $1(1.0 \%)$ solitary fibrous tumor, and $1(1.0 \%)$ schwannoma. In contrast, RCC was diagnosed in 83 cases $(86.4 \%)$, consisting of 75 cases $(78.1 \%)$ of clear cell RCC, 2 cases $(2.1 \%)$ of papillary RCC, 2 cases (2.1\%) of cystic RCC, 4 cases $(4.2 \%)$ of unclassified RCC, and no cases $(0 \%)$ of chromophobe RCC.

To clarify the incidence of benign lesions according to nodule size, we categorized nodules by $1-\mathrm{cm}$ increments in diameter (table 2). The incidence of benign lesions was $25.0 \%$ for nodules $<1 \mathrm{~cm}, 23.8 \%$ for nodules $1-1.9 \mathrm{~cm}, 11.5 \%$ for nodules $2-2.9 \mathrm{~cm}, 7.7 \%$ for nodules $3-3.9 \mathrm{~cm}$, and $7.1 \%$ for nodules $4 \mathrm{~cm}$.

The data were analyzed using a logistic regression model with age, gender, nodule size, and imaging type as variables (table 3 ). Univariate analyses showed that younger age $(<60$ years), female gender, and smaller nodule size $(<3 \mathrm{~cm})$ were significant risk factors for benign lesions. Multivariate analysis confirmed that younger age $(<60$ years) (odds ratio $[\mathrm{OR}]=5.23$ ), female gen$\operatorname{der}(\mathrm{OR}=4.78)$ and smaller nodule size $(<3 \mathrm{~cm})(\mathrm{OR}=$ 6.14) were independent determinants of risk for a benign lesion.
The actual incidence of benign lesions in cases with two risk factors was $33.3 \%$ (6/18) for young females, $31.8 \%(7 / 22)$ for younger age with small nodule size, and $33.3 \%(7 / 21)$ for females with a small nodule size. The incidence of cases with triple risk factors was extremely high at $50 \%(4 / 8)$.

\section{Discussion}

This study determined the incidence of benign renal nodules obtained by surgery in Japanese patients with a suspicious mass detected by preoperative radiology. The incidence of benign lesions (13.5\% of total cases) was relatively low compared with recent reports from Western countries [1-3].

The rate of benign lesions after either radical or partial nephrectomy in our study ( $13.5 \%$ of total cases, $24.1 \%$ for nodules $<2 \mathrm{~cm}$ and $7.7 \%$ for nodules between 2 and $4 \mathrm{~cm})$ was similar to that reported by Fujii et al. $(10.58 \%$ of total cases, $12.4 \%$ for nodules $<2 \mathrm{~cm}$ and $8.9 \%$ for nodules between 2 and $4 \mathrm{~cm}$ ) [4], but lower than the incidence for nodules $<2 \mathrm{~cm}$, and marginally higher than in our previous study of Japanese patients ( $4.4 \%$ of total cases, $16.2 \%$ for nodules $<2 \mathrm{~cm}$ and $4.8 \%$ of nodules 
between 2 and $4 \mathrm{~cm}$ ) [5]. The current study evaluated the reasons for these differences.

As a first possibility, we examined the distribution of different types of benign nodules and found that the incidence of oncocytoma was markedly different in the current study (6 cases, $6.2 \%$ of total cases) than in our previous report (4 cases, $1.0 \%$ of total cases) [5]. Because CT imaging of oncocytoma is similar to RCC [9], a high incidence of oncocytoma may directly increase the incidence of benign lesions, without predicting oncocytoma preoperatively.

Another possibility is that there are other options for treating suspicious renal masses, including ablation. We previously reported that radio frequency ablation (RFA) was suitable as an optimal ordinary option for small renal nodules [10]. However in the current report, ordinary treatment options also included active surveillance, partial nephrectomy, and radical nephrectomy, but did not include ablation. It is possible this may have affected decisions regarding renal nodules, especially whether or not surgical treatment was necessary. In high volume centers using ablation, small nodules with a slightly high risk of co-morbidities are considered as suitable for ablation rather than surgery. In contrast, at centers carrying out a low volume of ablations, cases in which there is any suspicion of a renal nodule and a slight risk of co-morbidities are selected for surgery or active surveillance, rather than ablation. Kunkle et al. [11] also reported that $37.8 \%$ of cases received RFA without a renal biopsy, and that $33.5 \%$ of cases had an unknown or indeterminate pathology. Their study showed that the pathological findings of over $30 \%$ of the cases with RFA were uncertain, while another study showed only a small number of cases received RFA in combination with a renal biopsy [10].

We therefore suspect that the majority of cases in each institution who have RFA without a definite pathological result may affect the background for selecting surgical candidates, thereby contributing to the incidence of benign renal nodules treated by surgery, especially small nodules.

In order to devise treatment strategies it is essential to identify predictive factors which can be estimated in the preoperative stage. In this study we demonstrated that significant predictive factors that prognosticated the presence of benign renal nodules include younger age $(<$ 60 years old), female gender, and smaller tumor size (< $3 \mathrm{~cm}$ ). We also examined the predictive factors for renal benign nodules with suspicious RCC reported in several studies $[1-3,5,12]$ (table 4). The incidence of benign lesions in all cases ranged between 4.4 and $21.5 \%$, with the current study having the second lowest incidence in the summary. All the reports suggested that female gender was a predictor for the presence of benign nodules, while smaller size was also a factor in 4 of the 6 reports.

The question of how to deal with predictive factors in devising a treatment strategy for small renal nodule needs to be addressed. We analyzed the actual number of benign incidents in our cases according to the number of predictive factors. The incidence of benign lesions was $31.8-33.3 \%$ in cases with 2 risk factors and 50\% (4/8) in cases with 3 factors. This finding indicates that it is possible to identify candidates with a higher risk for a benign pathological finding, and that these cases should be considered as suitable candidates for a preoperative biopsy of the renal nodule or active surveillance. This treatment strategy would also assist in making decisions on future treatment options [13-15]. Future prospective studies should therefore assess whether a preoperative renal biopsy or active surveillance in cases with a high risk of benign pathological findings decreases the incidence of indications for surgery for benign renal nodules.

Our study had the limitation of being a retrospective investigation in a small cohort of patients. However, determining the actual incidence of benign nodules among renal nodules obtained by surgery, based on recent preoperative radiological evaluations at each institution is crucial for effective management of these lesions. Our findings suggest that ordinary treatment options affect the choice of surgical candidates and contribute to differences in the incidence of benign nodules being diagnosed.

\section{Conclusions}

The incidence of benign renal nodules $(13.5 \%$ of total cases) in this study is lower than that reported in recent studies in Western countries. Significant predictive factors for benign renal nodules include younger age $(<60$ years), female gender, and small tumor size $(<3 \mathrm{~cm})$. We consider that these 3 factors should be used as predictors of benign renal nodules. 


\section{References}

1 Snyder ME, Bach A, Kattan MW, Raj GV, Reuter VE, Russo P: Incidence of benign lesions for clinically localized renal masses smaller than $7 \mathrm{~cm}$ in radiological diameter: influence of sex. J Urol 2006;176:2391-2395.

-2 Jeon HG, Lee SR, Kim KH, Oh YT, Cho NH, Rha KH, Yang SC, Han WK: Benign lesions after partial nephrectomy for presumed renal cell carcinoma in masses $4 \mathrm{~cm}$ or less: prevalence and predictors in Korean patients. Urology 2010;76:574-579.

-3 Akdogan B, Gudeloglu A, Inci K, Gunay LM, Koni A, Ozen H: Prevalence and predictors of benign lesions in renal masses smaller than 7 $\mathrm{cm}$ presumed to be renal cell carcinoma. Clin Genitourin Cancer 2012;10:121-125.

-4 Fujii Y, Komai Y, Saito K, Iimura Y, Yonese J, Kawakami S, Ishikawa Y, Kumagai J, Kihara $\mathrm{K}$, Fukui I: Incidence of benign pathologic lesions at partial nephrectomy for presumed RCC renal masses: Japanese dual-center experience with 176 consecutive patients. Urology 2008;72:598-602.

5 Soga N, Nishikawa K, Takaki H, Yamada Y, Arima K, Hayashi N, Sugimura Y: Low incidence of benign lesions in resected suspicious renal masses greater than $2 \mathrm{~cm}$ : single-center experience from Japan. Int J Urol 2012;19:729-734.
6 Ferda J, Hora M, Hes O, Reischig T, Kreuzberg B, Mirka H, Ferdova E, Ohlidalova K, Baxa J, Urge T: Computed tomography of renal cell carcinoma in patients with terminal renal impairment. Eur J Radiol 2007;63:295301.

$7 \mathrm{Wu} Y \mathrm{H}$, Song B, Gong QY, Wu B, Chen WX, Liu RB, Wu B, Li ZL: Renal and non-renal tumors within the perirenal space in infants and children: multi-detector row CT characteristics. Sichuan Da Xue Xue Bao Yi Xue Ban 2010;41:288-291.

$>8$ Israel GM, Bosniak MA: An update of the Bosniak renal cyst classification system. Urology 2005;66:484-488.

$>9$ Choudhary S, Rajesh A, Mayer NJ, Mulcahy KA, Haroon A: Renal oncocytoma: CT features cannot reliably distinguish oncocytoma from other renal neoplasms. Clin Radiol 2009;64:517-522.

10 Takaki H, Yamakado K, Soga N, Arima K, Nakatsuka A, Kashima M, Uraki J, Yamada T, Takeda K, Sugimura Y: Midterm results of radiofrequency ablation versus nephrectomy for T1a renal cell carcinoma. Jpn J Radiol 2010;28:460-468.
1 Kunkle DA, Uzzo RG: Cryoablation or radiofrequency ablation of the small renal mass: a meta-analysis. Cancer 2008;113:26712680.

12 Xiong YH, Zhang ZL, Li YH, Liu ZW, Hou GL, Liu Q, Yun JP, Zhang XQ, Zhou FJ: Benign pathological findings in 303 Chinese patients undergoing surgery for presumed localized renal cell carcinoma. Int J Urol 2011;17: 517-521.

13 Lane BR, Samplaski MK, Herts BR, Zhou M, Novick AC, Campbell SC: Renal mass biopsy-a renaissance? J Urol 2008;179:20-27.

14 Schmidbauer J, Remzi M, Memarsadeghi M, Haitel A, Klingler HC, Katzenbeisser D, Wiener H, Marberger M: Diagnostic accuracy of computed tomography-guided percutaneous biopsy of renal masses. Eur Urol 2008; 53:1003-1011.

15 Halverson SJ, Kunju LP, Bhalla R, Gadzinski AJ, Alderman M, Miller DC, Montgomery JS, Weizer AZ, Wu A, Hafez KS, Wolf JS Jr: Accuracy of determining small renal mass management with risk stratified biopsies: confirmation by final pathology. J Urol 2013; 189:441-446. 